Properties of Plutonium-Containing Colloids Released from Glass-Bonded Sodalite Nuclear Waste Form

Lester R. Morss, Carol J. Mertz, A. Jeremy Kropf, and Jennifer L. Holly

Chemical Technology Division

Argonne National Laboratory

Argonne, IL 60439

For presentation at

Scientific Basis for Nuclear Waste Management XXV

Materials Research Society 2001 Fall Meeting

November 26-30, 2001

Boston, MA

The submitted manuscript has been created by the University of

Chicago as Operator of Argonne National Laboratory

("Argonne") under Contract No. W-31-109-ENG-38 with the

U.S. Department of Energy. The U.S. Government retains for

itself, and others acting on its behalf, a paid-up, nonexclusive,

irrevocable worldwide license in said article to reproduce,

prepare derivative works, distribute copies to the public, and

perform publicly and display publicly, by or on behalf of the

Government.

*This work was supported by the U.S. Department of Energy, Nuclear Energy and Development Program, under contract W-31-109-ENG-38. 


\title{
Properties of Plutonium-Containing Colloids Released from Glass-Bonded Sodalite Nuclear Waste Form
}

Lester R. Morss, Carol J. Mertz, A. Jeremy Kropf, and Jennifer L. Holly

Chemical Technology Division, Argonne National Laboratory, Argonne, IL 60439

\begin{abstract}
In glass-bonded sodalite, which is the ceramic waste form (CWF) to immobilize radioactive electrorefiner salt from spent metallic reactor fuel, uranium and plutonium are found as 20-50 $\mathrm{nm}(\mathrm{U}, \mathrm{Pu}) \mathrm{O}_{2}$ particles encapsulated in glass near glass-sodalite phase boundaries. In order to determine whether the $(\mathrm{U}, \mathrm{Pu}) \mathrm{O}_{2}$ affects the durability of the $\mathrm{CWF}$, and to determine release behavior of uranium and plutonium during CWF corrosion, tests were conducted to measure the release of matrix and radioactive elements from crushed CWF samples into water and the properties of released plutonium. Released colloids have been characterized by sequential filtration of test solutions followed by elemental analysis, dynamic light scattering, transmission electron microscopy (TEM), and X-ray absorption spectroscopy. This paper reports the composition, size, and agglomeration of these colloids. Significant amounts of colloidal, amorphous aluminosilicates and smaller amounts of colloidal crystalline $(\mathrm{U}, \mathrm{Pu}) \mathrm{O}_{2}$ were identified in test solutions. The normalized releases of uranium and plutonium were significantly less than the normalized releases of matrix elements.
\end{abstract}

\section{INTRODUCTION}

Actinide elements, which are present in radioactive wastes principally as the long-lived radionuclides ${ }^{235} \mathrm{U},{ }^{237} \mathrm{~Np}$, and ${ }^{239} \mathrm{Pu}$, are relatively insoluble in the tetravalent oxidation state. The low solubility of compounds containing the tetravalent ions $\mathrm{U}^{4+}, \mathrm{Np}^{4+}$, and $\mathrm{Pu}^{4+}$ limits the transport of these nuclides in the groundwater that may infiltrate a repository. However, these radionuclides may migrate from nuclear waste as colloidal particles or may adsorb onto groundwater colloids or iron colloids generated from spent fuel cladding or canisters. The concentrations of actinide species in colloids can far exceed their true solubility as tetravalent ions, and their potential to migrate is greater than can be modeled on the basis of solubility limits. Therefore, it is appropriate to determine both the release of actinide colloids from waste forms and the important properties of actinide-bearing colloids.

Electrometallurgical treatment of spent sodium-bonded metallic fuel produces glassbonded sodalite, the ceramic waste form (CWF) that is used to immobilize the electrorefiner salt as well as the fission products and actinides in the salt. The CWF microstructure consists of $\sim 100-\mu \mathrm{m}$ sodalite granules surrounded by binder glass [1]. Small inclusions of oxides (uranium, plutonium, and some rare earths) and halite $(\mathrm{NaCl})$ are encapsulated by glass in the CWF near glass-sodalite phase boundaries. The uranium and plutonium oxides have been identified as clusters of $(\mathrm{U}, \mathrm{Pu}) \mathrm{O}_{2}$ particles of colloidal size $(20-50 \mathrm{~nm})$ [2]. A transmission electron micrograph of these particles in CWF is shown in figure 1 (left). Knowledge of the properties of the colloids released during CWF corrosion will be important for its qualification for disposal in a federal repository. The techniques developed to characterize these colloids will also be useful to characterize radiocolloid releases from other waste forms. 


\section{DESCRIPTION OF CERAMIC WASTE FORM AND CORROSION TESTS}

Samples of CWF that had been loaded with 0.15-0.43 mass\% U and Pu were prepared by hot isostatic pressing (HIPing) at $850^{\circ} \mathrm{C}$ or by ambient-pressure consolidation at $915^{\circ} \mathrm{C}$. Specimens were crushed and sieved to isolate the $-100+200$-mesh fraction, washed in absolute ethanol to remove fines, and washed in water to measure the rapid-water-soluble release of $\mathrm{Cl}^{-}$, which represents the halite exposed during crushing. Product consistency tests (PCTs) [3] with this $\mathrm{CWF}$ in demineralized water at $90^{\circ} \mathrm{C}$ for test durations of 7 through 365 days were used to determine the release of $\mathrm{Pu}$ [4]. The releases of matrix elements, simulated fission products, and actinides from $\mathrm{CWF}$ were determined. This paper focuses on the complementary techniques that characterized the released $(\mathrm{U}, \mathrm{Pu}) \mathrm{O}_{2}$ colloids in these tests.
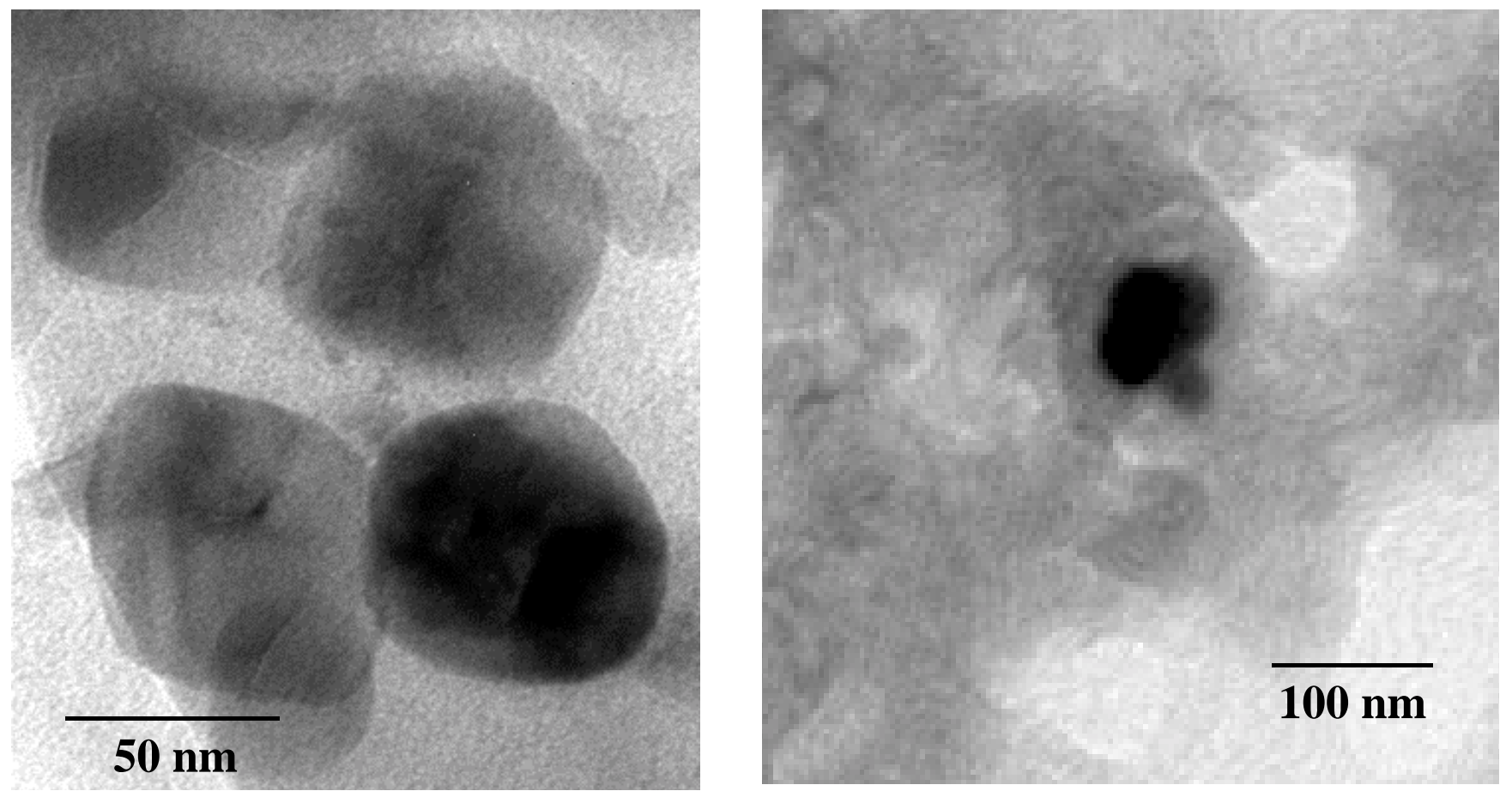

Figure 1. TEM images of $(\mathrm{U}, \mathrm{Pu}) \mathrm{O}_{2}$ particles. Left: in uncorroded CWF; right: in colloid from corrosion test solution.

\section{COLLOID DETERMINATION METHODOLOGY AND RESULTS}

\section{$\underline{\text { Sequential filtrations }}$}

Sequential filtration provides a measure of the particle size ranges and concentrations of colloids released from the CWF. Test solutions were filtered sequentially through $0.45-\mu \mathrm{m}$ syringe filters, $0.1-\mu \mathrm{m}$ centrifugal filters, and $0.005-\mu \mathrm{m}$ centrifugal filters. Aliquots of each filtrate were analyzed chemically by ICP-MS.

Typical PCT solution concentrations of matrix elements (boron in glass; aluminum and silicon in sodalite) in filtrates are shown in table I. The similar boron concentrations in all three filtrates show that negligible boron is found in colloids. The decreased $\mathrm{Al}$ and Si concentrations in the $0.005-\mu \mathrm{m}$ filtrates indicate that some aluminosilicate colloids are in the $0.005-0.1-\mu \mathrm{m}$ size 
range. Typical PCT solution concentrations of $\mathrm{Nd}$ (a lanthanide that represents the behavior of +3 actinide ions), $\mathrm{U}$ (present primarily as $\mathrm{UO}_{2}{ }^{2+}$ ), and $\mathrm{Pu}$ (present primarily as $\mathrm{Pu}^{4+}$ ) are also shown in table I. The dramatically lower concentrations of $\mathrm{Nd}$ and $\mathrm{Pu}$ in $0.005-\mu \mathrm{m}$ filtrates show that trivalent and tetravalent lanthanide and actinide ions are present mostly in 0.005-0.1$\mu \mathrm{m}$ colloids in the test solutions. The $\mathrm{Pu}$ concentration found in solution (in the $0.005-\mu \mathrm{m}$ filtrate) is similar to the saturated concentration of $\mathrm{Pu}^{4+}$ in carbonate-saturated water at $\mathrm{pH} 9$.

Table I. Solution concentrations of matrix elements, $\mathrm{Nd}, \mathrm{U}$, and $\mathrm{Pu}$ from (U/Pu)-loaded CWF in $90^{\circ} \mathrm{C} 7$-day PCTs vs. particle size range. Concentrations are averages from tests with the four CWF materials. Fractions adsorbed on vessel walls are not included.

\begin{tabular}{lcccccc}
\hline & \multicolumn{5}{c}{ Solution concentration $(\mathrm{mg} / \mathrm{L})$; estimated uncertainty $\pm 20 \%$} \\
\cline { 2 - 7 } & $\mathrm{B}$ & $\mathrm{Al}$ & $\mathrm{Si}$ & $\mathrm{Nd}$ & $\mathrm{U}$ & $\mathrm{Pu}$ \\
\hline $0.45-\mu \mathrm{m}$ filtrate & 6.5 & 24 & 35 & 0.0038 & 0.0024 & 0.0071 \\
$0.1-\mu$ m filtrate & 7.1 & 24 & 36 & 0.0025 & 0.0013 & 0.0048 \\
$0.005-\mu$ m filtrate & 7.3 & 16 & 28 & 0.0001 & 0.0005 & 0.0003 \\
\hline
\end{tabular}

The distribution of $\mathrm{B}, \mathrm{Si}$, and $\mathrm{Pu}$ fractions (normalized to the mass fraction of each element in the CWF) in a typical test is shown in table II. The 0.005-0.1- $\mu \mathrm{m}$ colloidal $\mathrm{Pu}$ fraction was the larger than the dissolved and 0.1-0.45 $\mu \mathrm{m}$ fractions. The amount of $\mathrm{Pu}$ deposited on the stainless-steel vessel walls was larger than all other fractions combined.

Table II. Normalized B, Si, and Pu mass loss fractions from 7-day PCT of U,Pu-loaded CWF.

\begin{tabular}{lccc}
\hline & \multicolumn{3}{c}{ Normalized mass loss $\left(\mathrm{g} / \mathrm{m}^{2}\right)$} \\
\cline { 2 - 4 } & $\mathrm{B}$ & $\mathrm{Si}$ & $\mathrm{Pu}$ \\
\hline Dissolved $(\leq 0.005 \mu \mathrm{m})$ & 0.214 & 0.064 & 0.00002 \\
Small colloids $(0.005-0.1 \mu \mathrm{m})$ & 0.007 & 0.018 & 0.00073 \\
Large colloids $(0.1-0.45 \mu \mathrm{m})$ & 0.009 & 0.002 & 0.0002 \\
Fixed to vessel walls & 0.019 & 0.020 & 0.024 \\
Total & 0.25 & 0.10 & 0.025 \\
\hline
\end{tabular}

\section{Dynamic light scattering (DLS)}

Aliquots of $0.45-\mu \mathrm{m}$ filtrates $(0.4-0.5 \mathrm{~mL})$ were placed in glass DLS vials immediately after filtration and were stored at $25^{\circ} \mathrm{C}$ until DLS measurements were made. The DLS apparatus is a modified 4700c Photon Correlation Spectrometer (Malvern Instruments) with a 3-75-mW argon ion laser. A correlator records the scattering intensity from small scattering volumes in time intervals as short as $50 \mathrm{~ns}$. Particle sizes in these polydisperse solutions were determined with CONTIN software [5-7]. Particle size calibration was performed using polystyrene latex standards (nominal sizes of 30,70,100, and $300 \mathrm{~nm}$ ). CONTIN analyzes data that are illconditioned (where an infinite number of mathematical solutions are possible), selecting a result from several that are generated during the analysis by minimizing the residual between the 
autocorrelation function derived from the experimental spectrum and that generated by model calculations. The results generated are based upon statistical constraints, in particular (1) a priori knowledge of the experimenter and (2) parsimony (the choice of the simplest solution among those not eliminated by constraints). Multiple DLS measurements were performed on each sample by varying scanning time to gain confidence in the result. The calculated size distributions are independent of scan time and indicate a stable colloidal system. Bimodal size distributions, represented by figure 2 , were found.

Figure 2. Intensity-weighted colloid size distribution in CWF test solution after 7-day PCT at $90^{\circ} \mathrm{C}$. Bimodal size distribution: mean diameters 8 and $120 \mathrm{~nm}$, peak areas $68 \%$ and 32\%.

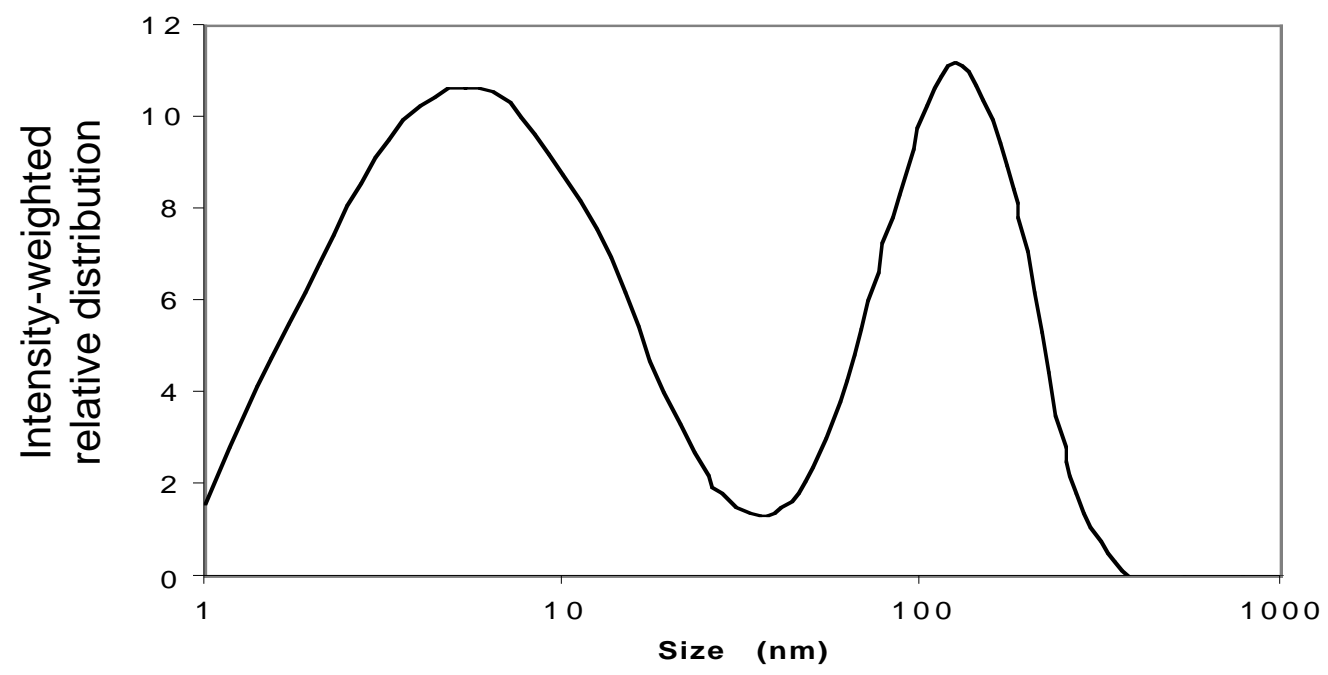

Transmission electron microscopy (TEM)

Colloidal particles were deposited on a lacey carbon TEM grid by pipetting a $5-\mu \mathrm{L}$ aliuqot of $0.45-\mu \mathrm{m}$ filtered test solution and wicking the liquid through the grid onto ethanolwetted filter paper. Because the concentration of colloids was rather low, most grids had only a few clusters of aluminosilicate colloids and no $(\mathrm{U}, \mathrm{Pu}) \mathrm{O}_{2}$ particles. Some grids were prepared by centrifuging the colloids from test solutions onto a grid held perpendicular to the centrifuge rotation axis in an epoxy support with a flat-bottom shallow cavity drilled out to support the grid. The grids were examined on a JEOL 2000 FXII transmission electron microscope operating at $200 \mathrm{kV}$, coupled with a Tracor Noran energy dispersive X-ray spectrometer.

A very few grids showed individual $(\mathrm{U}, \mathrm{Pu}) \mathrm{O}_{2}$ particles of about the same size $(20-50 \mathrm{~nm})$ as the particles in the $\mathrm{CWF}$ (figure 1, right). These $(\mathrm{U}, \mathrm{Pu}) \mathrm{O}_{2}$ particles were crystalline, exhibiting the expected fcc fluorite structure of $\mathrm{PuO}_{2}$. Most grids showed numerous $\sim 10-\mathrm{nm}$ aluminosilicate particles that were shown to be amorphous by their inability to display an electron diffraction pattern. Some of these particles appeared to be aggregated into $\sim 100-\mathrm{nm}$ clusters (figure 3 ). 


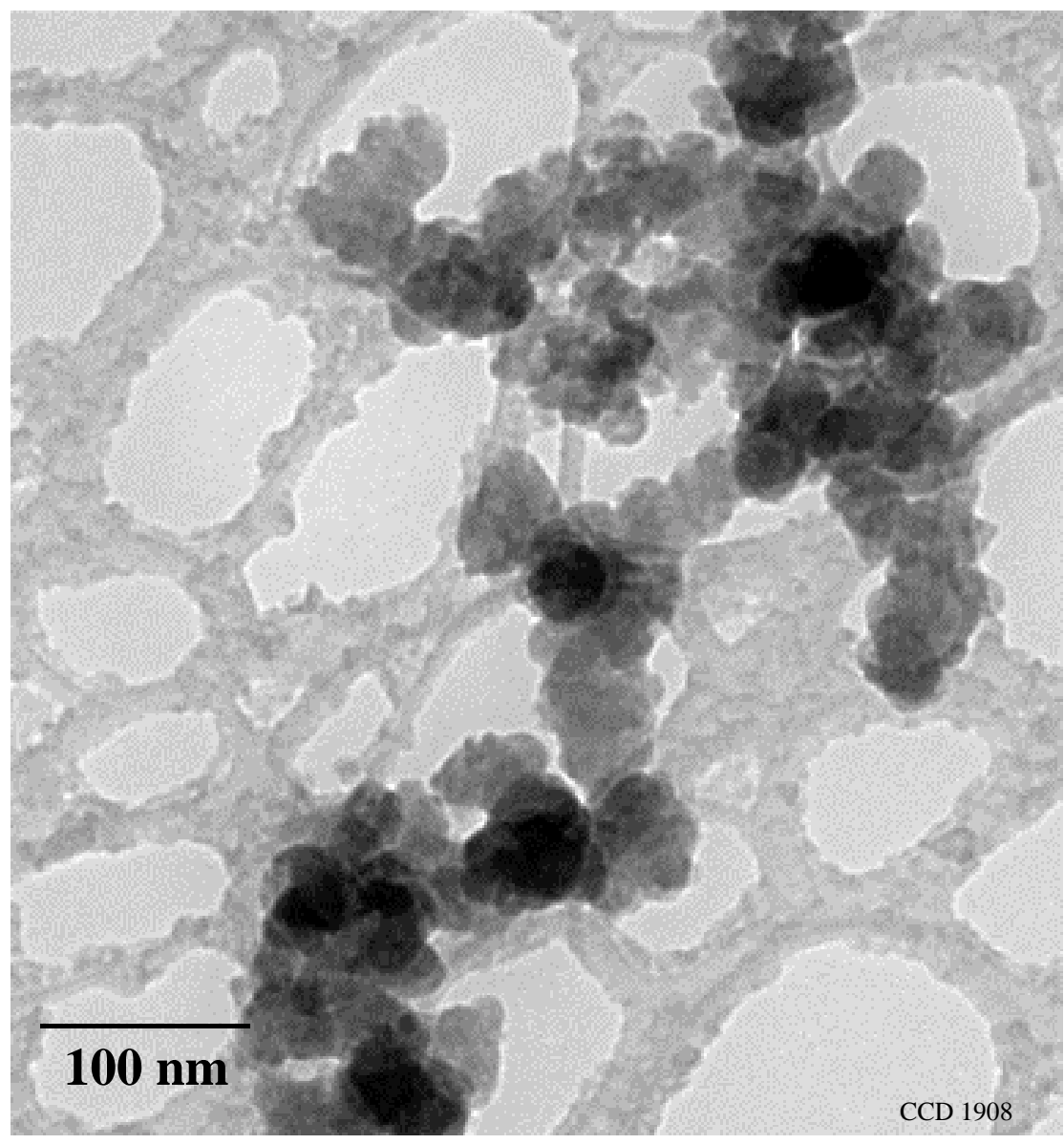

Figure 3. TEM image showing amorphous aluminosilicate particles from CWF test solution.

\section{$\underline{\text { X-ray absorption spectroscopy (XAFS) }}$}

To identify the geometrical distribution of plutonium on a centrifugal filter and, if possible, to confirm that the plutonium was present as $\mathrm{PuO}_{2}$, the $0.005-\mu \mathrm{m}$ centrifugal filter that retained the highest concentration of $\mathrm{Pu}$ (as determined from ICP-MS analyses of the filtrate before and after passing through the $0.005-\mu \mathrm{m}$ filter) was cut out of its support with a razor blade and mounted with epoxy in an XAFS holder. The holder was placed in the MR-CAT beamline at the ANL Advanced Photon Source, and XAFS scans were done at the $\mathrm{Pu}_{\mathrm{III}}$ edge. Fig. 4 is an area scan showing that the Pu-containing colloidal particles collected at part of the periphery of the filter. This region, shown at the right side of Fig. 4, was presumably the upper edge in the microcentrifuge, which had the highest centrifugal force. (The microcentrifuge holds filters at a $45^{\circ}$ angle, so the upper edge of the filter is subjected to the greatest centrifugal force.)

Figure 5 is a near-edge spectrum of these particles, which is compared with the spectrum of a reference $\mathrm{PuO}_{2}$ sample. The similarity of the two spectra leads to the conclusion that the $\mathrm{Pu}$ containing colloids on the filter contain tetravalent plutonium, which is consistent with the $\mathrm{PuO}_{2}$ found on TEM grids. The plutonium-containing species in uncorroded U,Pu-loaded CWF had previously been identified as $\mathrm{PuO}_{2}$ from $\mathrm{Pu} \mathrm{L}_{\text {III }}$ edge spectra [8]. 


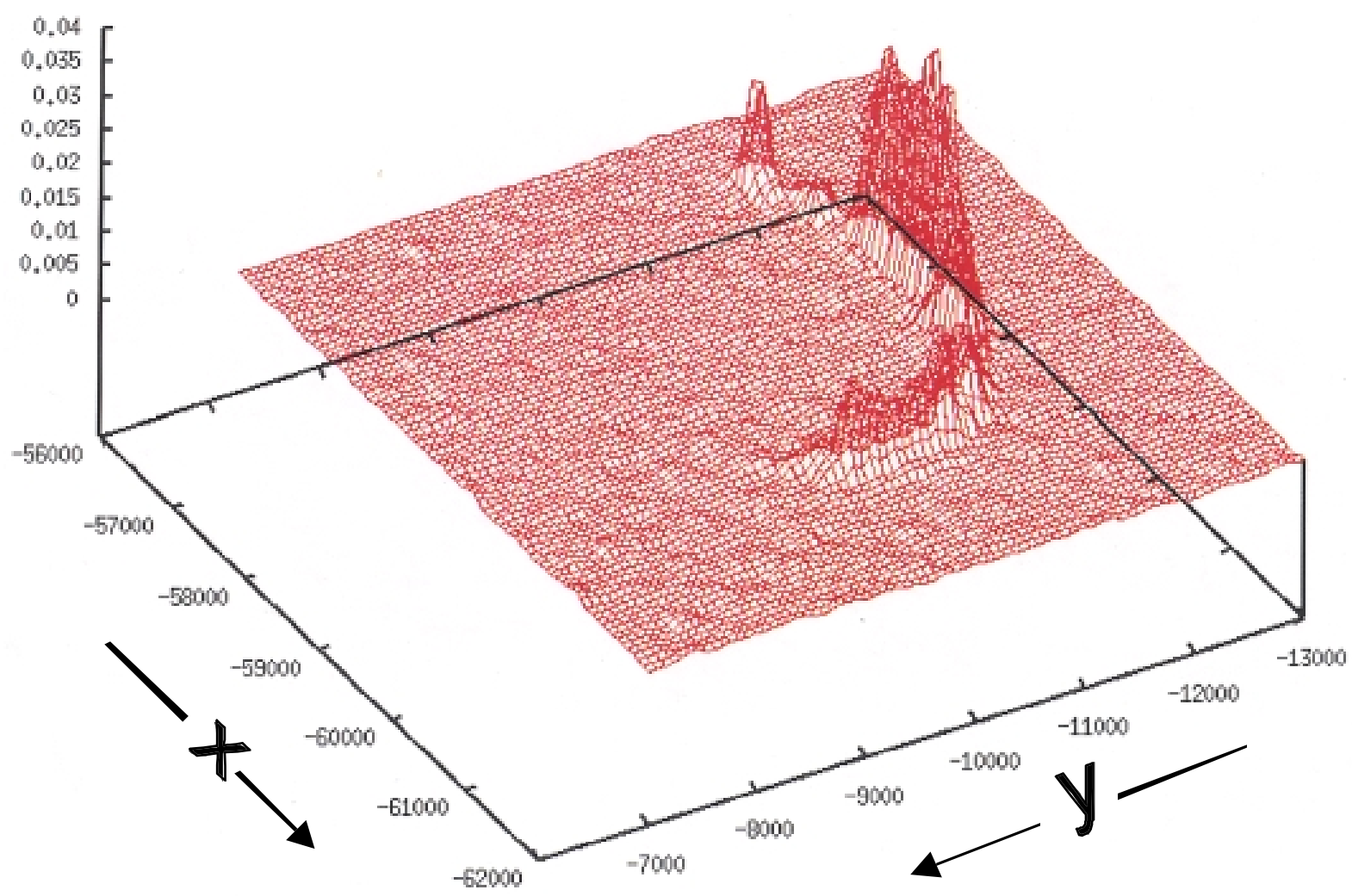

Figure 4. $\mathrm{Pu} \mathrm{L}_{\mathrm{III}}$ edge absorption area scan of the $0.005-\mu \mathrm{m}$ filter from $120^{\circ} \mathrm{C} \mathrm{PCT}$ after 225 days. The $x$ and $y$ axes are the geometric dimensions of the sample support stage in micrometers.

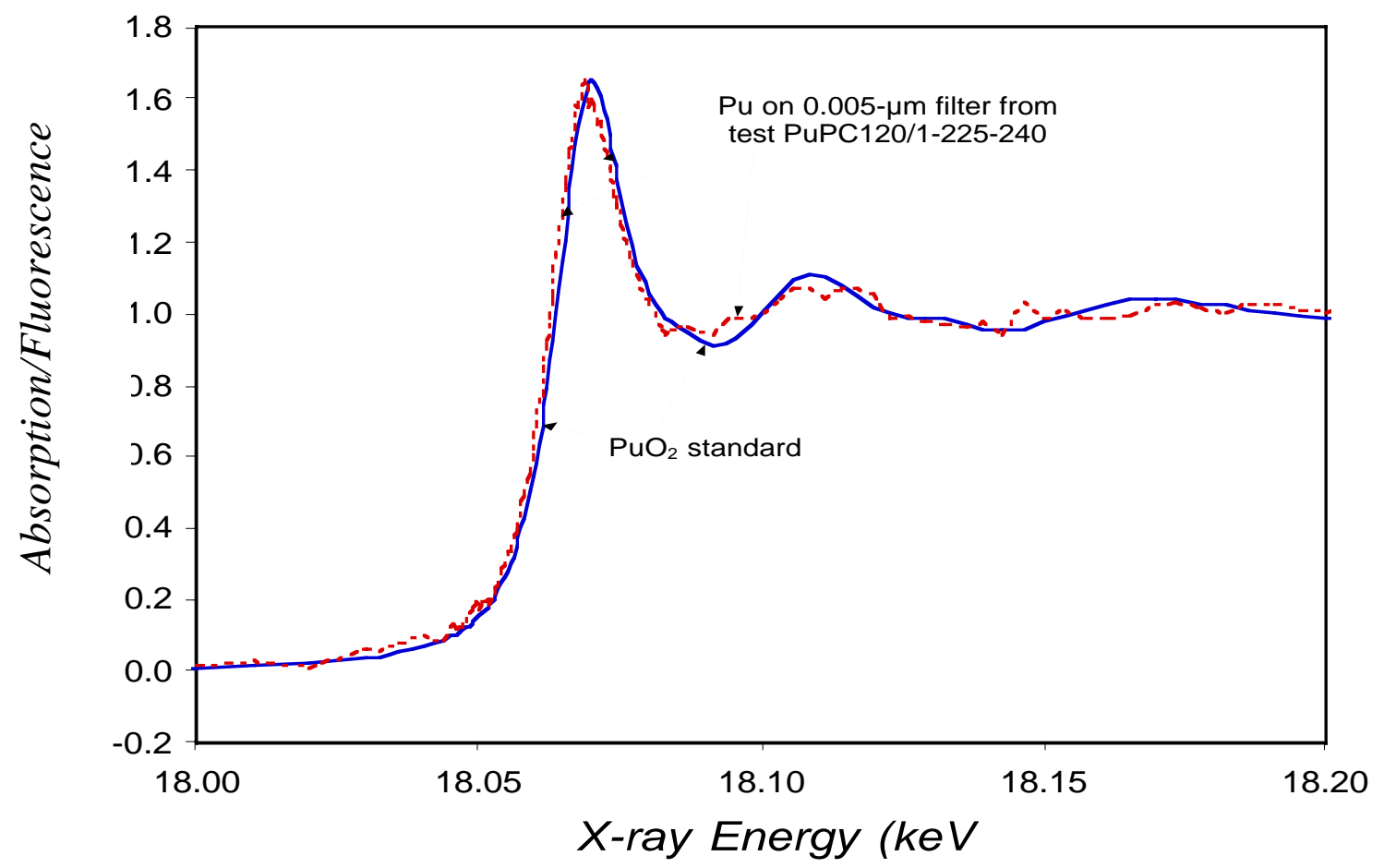

Figure 5. Absorption XAFS spectra of $\mathrm{Pu} \mathrm{L} \mathrm{L}_{\mathrm{III}}$ edges of reference $\mathrm{PuO}_{2}$ standard (smooth curve) and of $0.005-\mu \mathrm{m}$ filter from $120^{\circ} \mathrm{C}, 225$ day PCT (dashed curve). 


\section{SUMMARY}

1. A suite of colloid characterization techniques has been developed to characterize the size and chemical composition of colloids released from nuclear waste forms into solution.

2. Sequential filtration of test solutions following PCTs of the (U,Pu)-loaded glass-bonded sodalite ceramic waste form showed that the solutions contained many $0.005-0.1-\mu \mathrm{m}$ aluminosilicate colloidal particles. Most of the plutonium was present as $(\mathrm{U}, \mathrm{Pu}) \mathrm{O}_{2}$ colloids in the $0.005-0.1-\mu \mathrm{m}$ size range. The normalized releases of uranium and plutonium were significantly less than the normalized releases of matrix elements.

3. Dynamic light scattering of $0.45-\mu \mathrm{m}$ filtrates showed that there is typically a bimodal distribution of colloids. The two groups of colloidal particles are ca. 0.01 and $0.12 \mu \mathrm{m}$ in size.

4. Transmission electron microscopy of colloids deposited from $0.45-\mu \mathrm{m}$ filtrates onto wicked and centrifuged lacey carbon foils showed substantial amounts of $\sim 10 \mathrm{~nm}$ aluminosilicate colloids or clusters of these colloids and smaller amounts of colloidal crystalline $(\mathrm{U}, \mathrm{Pu}) \mathrm{O}_{2}$. The colloidal size distribution is consistent with that found by sequential filtration and DLS. The $\mathrm{PuO}_{2}$ particles that were found appear to be associated with aluminosilicate aggregates.

5. X-ray absorption spectroscopy mapping of colloidal material deposited on $0.005-\mu \mathrm{m}$ filters from sequential filtration showed that plutonium in the colloids is $\mathrm{Pu}^{4+}$ and has the coordination geometry of $\mathrm{PuO}_{2}$.

6. These characterization techniques establish that plutonium contained in glass-bonded sodalite is released during corrosion as $(\mathrm{U}, \mathrm{Pu}) \mathrm{O}_{2}$ colloids.

\section{REFERENCES}

1. W. L. Ebert, D. W. Esh, S. M. Frank, K. M. Goff, M. C. Hash, S. G. Johnson, M. A. Lewis, L. R. Morss, T. L. Moschetti, T. P. O’Holleran, M. K. Richmann, W. P. Riley, L. J. Simpson, W.

Sinkler, M. L. Stanley, C. D. Tatko, D. J. Wronkiewicz, J. P. Ackerman, K. Bateman, T. J. Battisti, D. G. Cummings, T. DiSanto, M. Gougar, K. Hirsche, L. Leibowitz, J. S. Luo, M. Noy, H. Retzer, M. F. Simpson, A. R. Warren, and V. N. Zyryanov, Ceramic Waste Form Handbook, Argonne National Laboratory Report ANL-NT-119.

2. W. Sinkler, T. P. O’Holleran, S. M. Frank, M. K. Richmann, and S. G. Johnson, in Scientific Basis of Nuclear Waste Management XXIII, edited by R.W. Smith and D.W. Shoesmith, (Mater. Res. Soc. Proc. 608, Pittsburgh, PA, 2000) pp. 423-429.

3. "Standard Test Methods for Determining Chemical Durability of Nuclear, Hazardous, and Mixed Wastes: The Product Consistency Test (PCT)," ASTM C 1285-97 12.01, West

Conshohocken, PA, pp. 694-711 (1999).

4. L. R. Morss and W. L. Ebert, submitted to Proceedings, Am. Ceram. Soc. Symp., Environmental issues and waste management technologies in the ceramic and nuclear industries VI, 2001.

5. S. W. Provencher, Comput. Phys. Commun. 27, 213-227 (1984).

6. S. W. Provencher, Comput. Phys. Commun. 27, 229-242 (1984).

7. R. S. Stock and W. H. Ray, J. Polymer Sci.: Polym. Phys. Ed., 23, 1393 (1985).

8. M. K. Richmann, D. T. Reed, A. J. Kropf, S. B. Aase, and M. A. Lewis, J. Nucl. Mater. 297, 303-312 (2001). 